\title{
$\mathrm{PH} 9 \mathbf{8}_{\text {actualidad }}$
}

\section{Un blog documenta el lado humano de la despoblación}

\begin{abstract}
"A todos los que tuvieron que marchar". Con esta frase encabeza Faustino Calderón su blog Los pueblos deshabitados. Veintiocho años lleva visitando estos lugares, con el deseo de documentar y mostrar el lado humano de la despoblación. A través de los testimonios de sus protagonistas: las personas que vivieron en estos pueblos. Este etnógrafo por afición ha recorrido incontables kilómetros y visitado más de mil pueblos de toda la geografía española. Para recuperar la memoria. La cultura. Porque, como también afirma en el inicio de su blog, "los pueblos deshabitados no son olvido, son cultura".
\end{abstract}

Faustino Calderón | autor del blog Los pueblos deshabitados

URL de la contribución <www.iaph.es/revistaph/index.php/revistaph/article/view/4428>

Mi pasión por la despoblación comenzó a finales de los años 80 cuando empecé a escuchar las canciones de Labordeta en las que hablaba sobre el abandono de numerosos pueblos en su tierra: Aragón. Cierto día cayó en mis manos un suplemento de una revista dominical de aquellos años donde salía un reportaje de un pueblo que se había quedado vacío: Villacadima, en la provincia de Guadalajara. Se mostraba una serie de fotografías en las que se veía el aspecto actual del pueblo acompañado de un texto donde narraba lo que fue y en lo que se había convertido Villacadima. Ese fin de semana puse rumbo a Villacadima para ver in situ lo que había leído en el reportaje y para, en cierto modo, visualizar también lo que el cantautor aragonés manifestaba con dolor y amargura en sus canciones. Salí impresionado de Villacadima. Pasear por sus calles y no ver un alma, las puertas de las casas abiertas de par en par con bastantes enseres en su interior, incluso la iglesia románica tenía la puerta abierta y se hacía presente el paso de los expoliadores.

¿Qué me causó más impresión? Todo. El silencio que allí se daba, la sensación de soledad tan abrumadora, el buen estado de las edificaciones que parecía que de un momento a otro fuera a entrar o salir gente, su entramado urbano donde esperabas que al doblar cualquier esquina te fueras a encontrar con alguien, pero no. Ni un ser viviente apareció durante mi estancia en Villacadima.

El viaje de vuelta lo hice ensimismado, ausente de otros pensamientos que no fuera lo que había visto hacía unas horas. Ese fue mi primer contacto con la despoblación. Quedé enganchado. Así hasta hoy en que ya supera el millar el número de pueblos deshabitados que he tenido ocasión de visitar.

Después de Villacadima vinieron más. Visité Sarnago, Aldealcardo, Taniñe, Tiermas, Ruesta, Castil de Carrias... y en todos ellos la misma emoción y las mismas sensaciones que en el primero. Siempre que podía, hacía una nueva escapada a visitar despoblados. Y amplié el radio de acción: Huesca, Lleida, Teruel, León, Albacete... Y siempre en soledad, por el puro placer de visitarlos. Y, sobre todo, haciendo trabajar la imaginación; con ella conseguía ver (imaginar) cómo era la vida en ellos. Tenía el decorado, yo tenía que poner los actores.

Esta afición no la compartía con nadie (porque tampoco sabía si había más gente que le gustara el tema). Hasta que la llegada de Internet lo cambió todo. Pensé que aquello que llevaba años visitando podía mostrarlo y compartirlo en las redes. Pronto comprobé que no era el único que tenía este hobby o pasión. Me propuse hacer el blog para dar a conocer muchos de estos lugares que se habían quedado vacíos en España. Quería darlos a conocer sí, pero también salvaguardar su memoria, evitar que cayeran en el olvido, que no fuera mostrar unas pocas fotografías y ya. Quería buscar el lado humano de la despoblación. Poner voz a las gentes que vivió en estos pueblos. Mostrar algo diferente, abordar la despoblación desde una visión poco tratada. No quería documentarme con archivos municipales, ni 


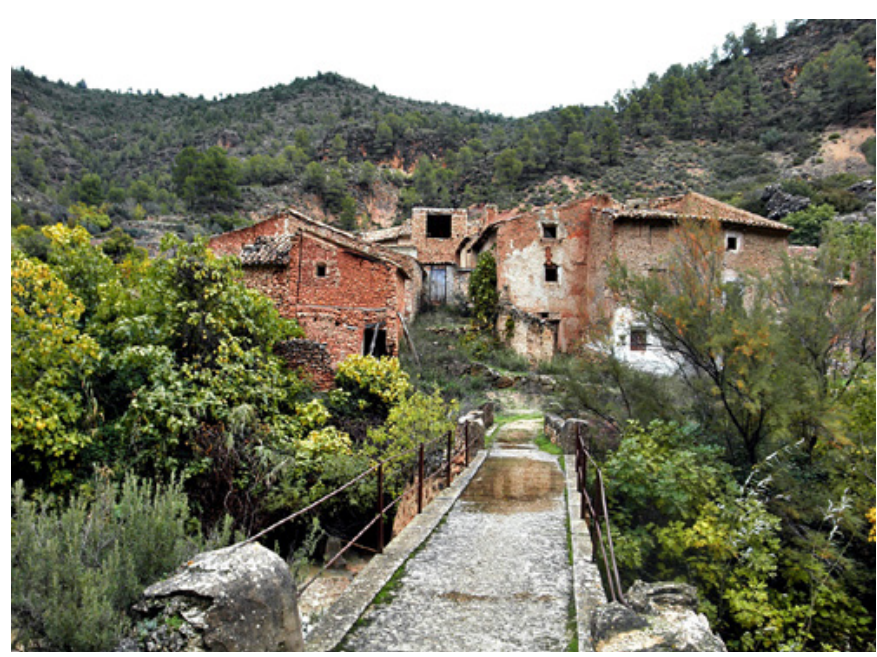

Alcadima (Albacete) | foto Faustino Calderón, autor de todas las imágenes que ilustran este texto

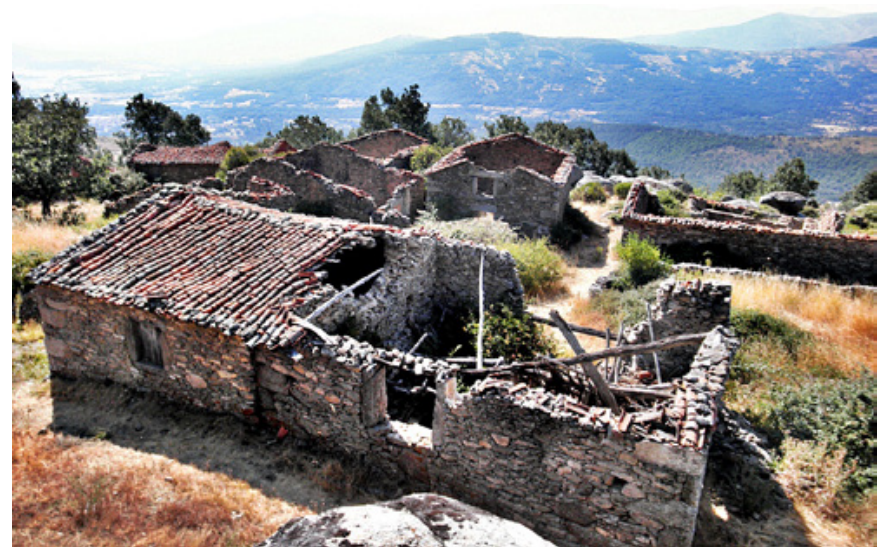

Casas de la Sierra (Ávila)

eclesiásticos, ni libros, sino conseguir la mejor fuente de información posible: los antiguos vecinos de cada pueblo.

Castarlenas en Huesca fue el primer pueblo donde me puse manos a la obra para buscar informantes. Después de visitar el despoblado, me acerqué hasta Torres del Obispo, el pueblo más cercano que lo había engullido a nivel administrativo. Allí pregunté por antiguos vecinos y me dieron referencias de dos. Contacté con ambos y el trato fue extraordinario: les extrañaba que viniera una persona de Madrid a interesarse por su pueblo, pero a la vez les halagaba y les llenaba de orgullo poder contar la vida pasada en él. Esto me animó a seguir por este
"La gente se marchaba porque la tierra ya no daba trabajo para todos, teníamos deficientes accesos, siempre caminos de caballería, el cierre de la escuela de Hijar también supuso un mazazo para los vecinos que quedaban porque los niños tenían que desplazarse a la de Ayna que les pillaba más retirado. La gente fue a probar suerte en las ciudades. Nosotros ya al final nos vinimos para Ayna y mi hermano Manuel todavía aguantó ocho meses más con su mujer y sus dos hijos pequeños viviendo en Alcadima, fueron los últimos en marchar, pero al final también se vinieron para Ayna, desde aquí podíamos seguir yendo a trabajar las tierras".

\section{ANTONIO GONZÁLEZ de Alcadima (Albacete)}

"La gente no emigró por pobreza como ocurrió en otras partes de España, la gente se marchó por falta de infraestructuras y servicios. La comida no escaseaba, vivíamos bien, pero nos faltaba todo lo demás. No había carretera, no había luz, no había agua corriente, para ir los niños a la escuela, las gentes a la iglesia, al cementerio, al médico, a cualquier gestión al ayuntamiento, etc, teníamos que bajar a Santa Lucia por un precario camino, lo que hacía todo muy difícil y la vida muy dura".

\section{MARÍA ROSA MARTÍN de Casas de la Sierra (Ávila)}

camino. ¿Quién mejor que las personas informantes me iban a contar detalles de la vida cotidiana del pueblo, de cómo se vivía, de las fiestas patronales, de la escuela, de la agricultura, de la ganadería, de los trayectos para realizar compras al pueblo grande, de los motivos de la marcha, etc.?

Seguí con el mismo método. Visitar y fotografiar el despoblado y luego buscar personas que hubieran vivido en dicho pueblo. En la mayoría de las ocasiones tenía suerte y conseguía encontrar alguna persona de las que me interesaba para saber acerca de ese despoblado. Disfrutaban contando, y yo, escuchando. Viajaban de alguna manera al pasado y yo lo hacía también. 


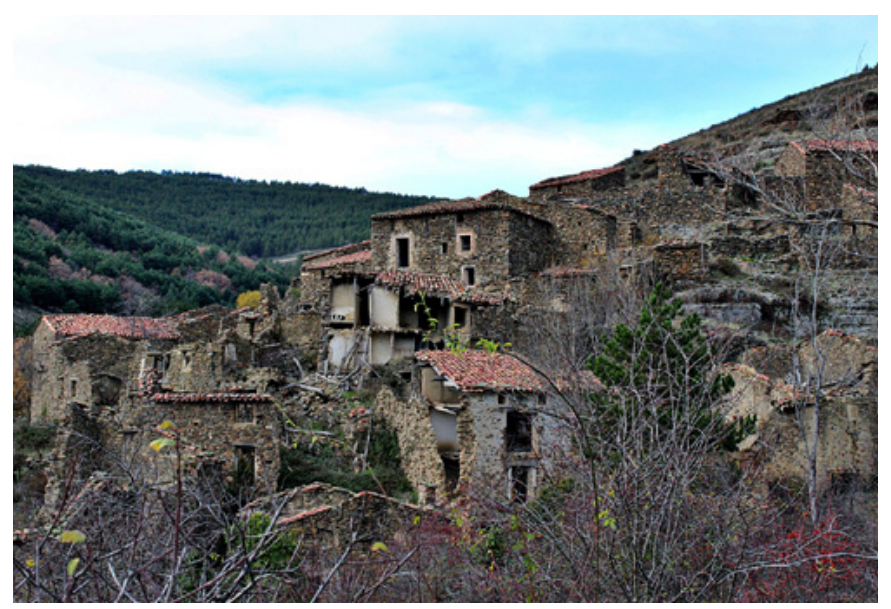

Valdemoro de San Pedro (Soria)

"Nuestra salida del pueblo fue el 16 de enero de 1959. Ese día nevaba, el pueblo estaba blanco y hacia mucho frío. Recuerdo pasar junto al cementerio y dando la vista atrás... allá quedaba nuestra cuna. Llevábamos pocas pertenencias, entre ellas una maquina de coser "Alfa", ropa y lana para los colchones, además de unas maletas que mi padre mandó hacer para la ocasión con madera de cerezo. Recuerdo escuchar a mi madre que se había hecho un pequeño bolso para esconder las pesetas y se lo puso dentro de la ropa. El itinerario fue Arnedo-Corella-Tudela-Barcelona y allí en el vapor "Salta" a Buenos Aires. Mi hermana Esperanza ya se había ido previamente puesto que allí vivían mis tíos Emilio y Antonia. El desarraigo y el posterior proceso de adaptación fue difícil, nos ayudábamos entre todos y aunque hubo momentos duros, conseguimos el objetivo. Argentina nos dio esperanza, trabajo y bienestar.Y nuestro querido Valdemoro siempre en el recuerdo".

ARACELI JIMÉNEZ de Valdemoro de San Pedro (Soria)

Pero aún así sabía que era (y es) una lucha contrarreloj. La mayoría de los pueblos se quedaron abandonados hace cincuenta años, por lo que muchas de las personas que allí vivieron ya han fallecido y las que no, son gente de edad avanzada. Me embarqué en la tarea de documentar el mayor número de despoblados posible sabiendo que los informantes iban a escasear cada vez más. Dentro de unos años ya no habrá nadie de pri-

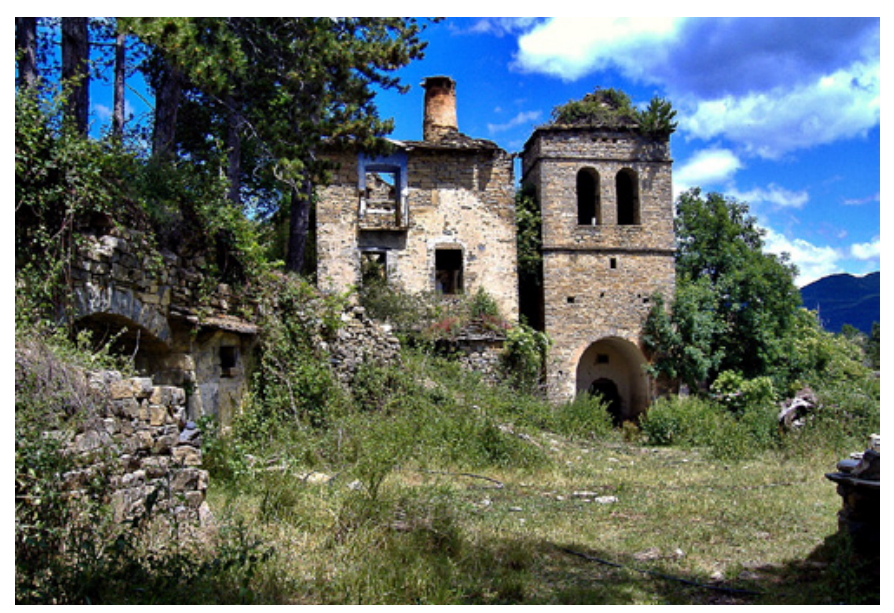

Ginuábel (Huesca)

"En el año 1979, más de quince años después de haber emigrado, subí a mi pueblo. Lo hacía en compañía de mi mujer y mis hijas que no conocían Ginuábel. Al llegar al pueblo donde yo había vivido los primeros veintisiete años de mi vida y tras la lógica emoción de los primeros momentos enseguida vi que ya nada era igual: las eras se habían convertido en simples espacios reducidos por los arbustos, los caminos y calles se habían cerrado a base de zarzales y sabuqueros, los huertos se habían convertido en una pequeña selva, de la fuente ya no manaba agua donde siempre había manado, mi casa tenía una parte del tejado hundido, había riesgo de entrar, la iglesia había sido utilizada como establo para las vacas, tuve que luchar duramente con las zarzas para poder ir abriendo camino. Todo me parecía un paisaje extraño, la vegetación estaba exuberante, los pinos que nunca hubo en mi pueblo ahora alcanzaban diez o doce metros de altura, era todo irreal, desolador".

\section{LUIS BUISÁN de Ginuábel (Huesca)}

mera mano que pueda decir que en tal despoblado se vivía así o que celebraban sus fiestas patronales de tal manera. Será la siguiente generación la que pueda aportar algo, pero ya no será lo mismo: yo le oí contar a mi padre, mi abuelo contaba que en una ocasión, siempre he oído contar a mi madre... Internet llegó tarde (para este trabajo que hago) porque antes me dedicaba a visitar despoblados sin más. En aquellos años todo habría 
sido más fácil (había más gente viva de las que vivieron en estos pueblos).

Soy consciente de que este trabajo no tendrá un final porque se quedará mucho sin hacer, pero hasta donde llegue he llegado y de los pueblos que he conseguido documentar ya se podrá saber un poco más en un futuro. Las generaciones venideras podrán saber cómo se vivía no hace muchos años en el pueblo de sus antepasados. Porque la importancia de contar en texto cómo eran estos lugares supera a lo que se pueda mostrar en fotografías.
"Nadie que no haya sufrido nada parecido podrá comprender el sufrimiento y sobre todo la impotencia de tener que dejarlo todo a la fuerza: tu casa, tus tierras y tantos recuerdos que quedaron allí enterrados para siempre. Las personas mayores fueron los que peor lo pasaron, el caso particular de mi padre, que durante el primer año en Zaragoza creíamos que no lo superaba, la tristeza le embargaba y aun hoy me emociono de recordarlo".

JOSÉ GARCÍA de Tiermas (Zaragoza)

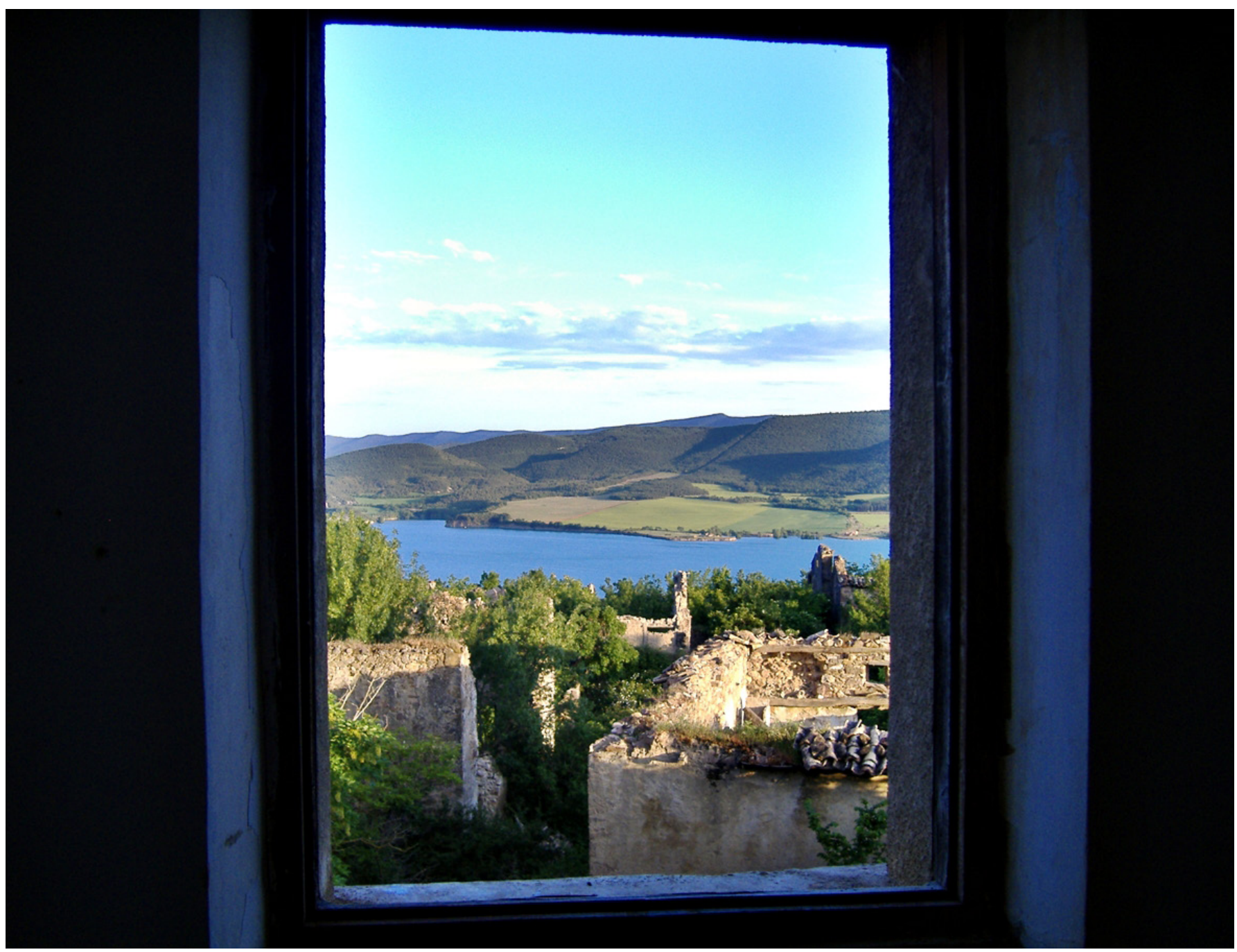

Tiermas (Zaragoza) 